\title{
Sperm as microswimmers - navigation and sensing at the physical limit
}

Ulrich B. Kaupp and Luis Alvarez ${ }^{\mathrm{a}}$

Center of Advanced European Studies and Research (caesar), Department of Molecular Sensory Systems, Ludwig-Erhard-Allee 2, 53175 Bonn, Germany

Received 1 April 2016 / Received in final form 27 May 2016 Published online 10 November 2016

\begin{abstract}
Many cells and microorganisms have evolved a motility apparatus to explore their surroundings. For guidance, these biological microswimmers rely on physical and chemical cues that are transduced by cellular pathways into directed movement - a process called taxis. Only few biological microswimmers have been studied as detailed as sperm from sea urchins. Sperm and eggs are released into the seawater. To enhance the chances of fertilization, eggs release chemical factors - called chemoattractants - that establish a chemical gradient and, thereby, guide sperm to the egg. Sea urchin sperm constitute a unique model system for understanding cell navigation at every level: from molecules to cell behaviours. We will outline the chemotactic signalling pathway of sperm from the sea urchin Arbacia punctulata and discuss how signalling controls navigation in a chemical gradient. Finally, we discuss recent insights into sperm chemotaxis in three dimensions (3D).
\end{abstract}

\section{Introduction}

Sperm carry a hair-like protrusion - called flagellum - emanating from the head. The beating flagellum propels the cell. Like most microswimmers, sperm live in a world where viscosity rules rather than inertia $[1,2]$. Under these conditions, the inertia terms in the Navier-Stokes equation can be neglected, and we obtain the simpler Stokes equation (a detailed account is provided by [3] in this issue):

$$
\eta \nabla^{2} \mathbf{v}=\nabla p
$$

where $\eta$ represents the dynamic fluid viscosity, $\mathbf{v}$ the flow speed, and $p$ the fluid pressure. Because of the time-reversibility of the Stokes equation, sperm cannot advance by simply flapping their flagellum in a time-reversible manner: after each beat cycle, the velocity and pressure will reverse, and sperm would move forward and backwards without advancing (Fig. 1(a)). Instead, a travelling wave propagates along the flagellum from the head to the flagellar tip. The movement is time-irreversible, because half of the beat cycle is not identical to the following half cycle played backwards (Fig. 1(b)).

For steering, sperm modulate the asymmetry of the flagellar beat. When the flagellum beats symmetrical with respect to the long axis of the ellipsoid-shaped

\footnotetext{
${ }^{a}$ e-mail: luis.alvarez@caesar.de
} 
a)

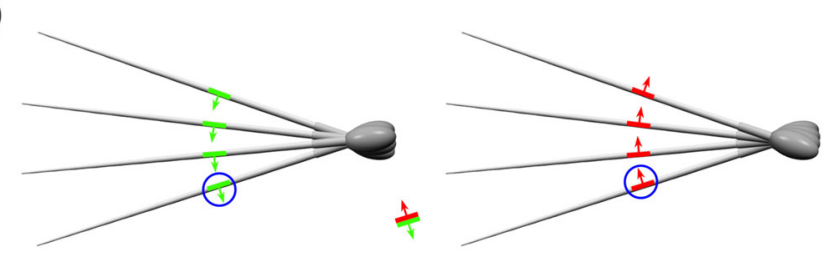

b)

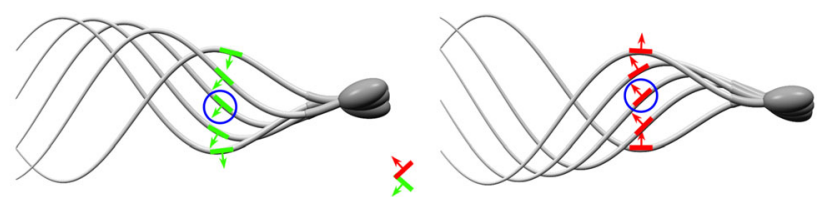

c)

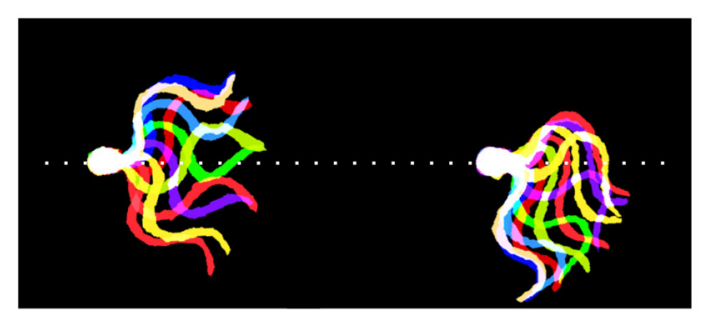

Fig. 1. (a) A time-reversible "microswimmer". Forces imposed by a small portion of the flagellum onto the fluid are shown. Because both halves of the beat cycle are identical, but reversed in direction, forces applied during one half of the cycle (green, left) are opposite to those produced during the other half (red, right); the "microswimmer" will not move forward. (b) Sperm break the temporal symmetry and both cycles differ, because the travelling wave propagates only in one direction. (c) Superposition of several images of a sperm cell while swimming straight (left) or turning (right). Pictures were acquired using dark-field microscopy and aligned with respect to the long axis of the ellipsoid-shaped head (dotted line). Figure adapted from [2].

head, sperm move on a straight path. When the flagellar beat becomes more asymmetric, the fluid is pushed aside and sperm turn (Fig. 1(c)). During chemotaxis, sperm couple stimulation by chemoattractants to the symmetry/asymmetry of the flagellar beat. Here, we summarize the signalling pathway and the physics of navigation during chemotaxis of sea urchin sperm. This review represents a summary of previous accounts $[2,4-8]$.

\section{Signalling pathways}

\subsection{Short overview}

Sperm chemotaxis has been primarily studied in sea urchins, but also in other marine invertebrates [9-13]. Sea urchins live in colonies on the sea floor and release eggs and sperm into the seawater, that is, fertilization happens externally. Upon spawning, sperm and eggs are dispensed on a macroscopic scale by water flow. Sea urchin eggs are about $75-150 \mu \mathrm{m}$ in diameter. To enlarge their effective target volume, eggs release species-specific chemoattractant peptides ( $~ 8$ to 15 amino acids in length). In particular, eggs from the sea urchin Arbacia punctulata release a 14 amino-acid peptide named resact. A back-of-the-envelope estimate suggests that sperm must reach an egg as close as about $0.5 \mathrm{~cm}$ to become attracted [14]. Thus, eggs increase their effective target volume by several orders of magnitude. 
a)

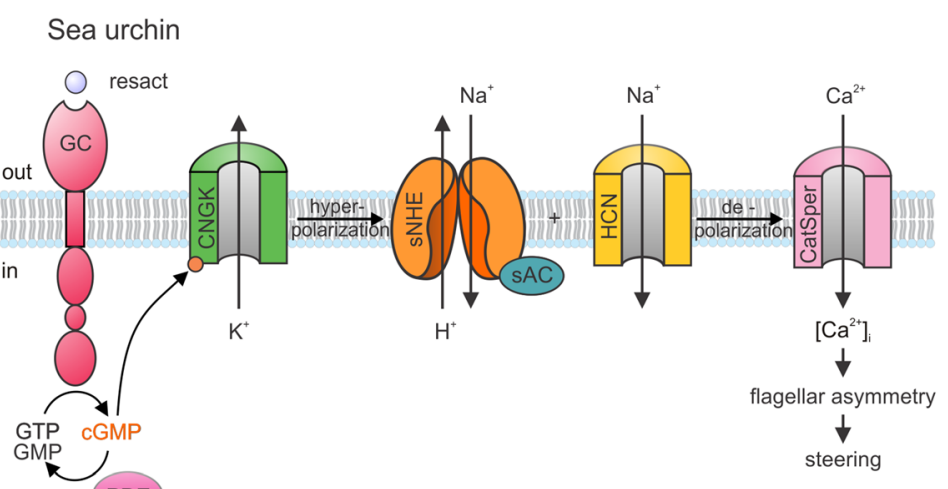

b)

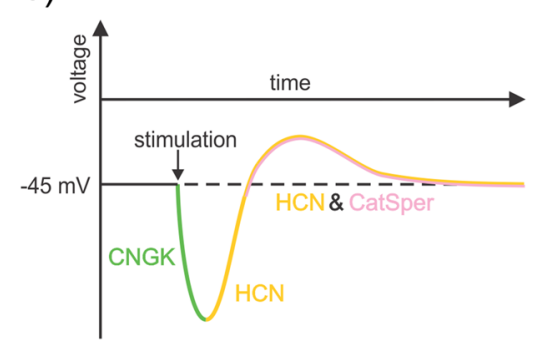

c)

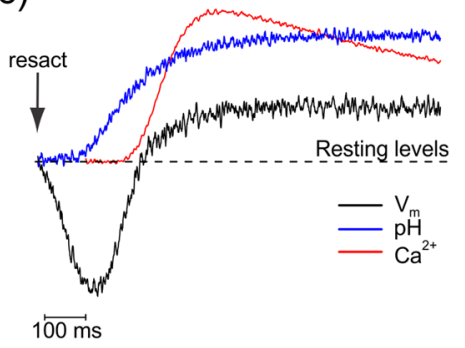

Fig. 2. Minimal model of signalling pathway controlling chemotactic steering of sperm from A. punctulata (see text for details). (a) Binding of the chemoattractant resact to the GC receptor stimulates synthesis of cGMP, which opens CNGK channels and the cell hyperpolarizes $\left(\mathrm{V}_{\mathrm{m}}\right.$ becomes more negative). Hyperpolarization is followed by intracellular alkalisation via a sodium/proton exchanger (sNHE), which shifts the voltage-dependence of the $\mathrm{Ca}^{2+}$ channel CatSper to more negative membrane potentials. As the cell depolarizes, CatSper channels open and $\mathrm{Ca}^{2+}$ flows in the cell, which changes the flagellar beat. (b) Scheme of changes in membrane voltage $\left(\mathrm{V}_{\mathrm{m}}\right)$ upon resact stimulation. Contributions of the CNGK, $\mathrm{HCN}$, and CatSper channels are highlighted in green, orange, and pink, respectively (c) $\mathrm{V}_{\mathrm{m}}$, $\mathrm{pH}_{\mathrm{i}}$, and intracellular $\mathrm{Ca}^{2+}$ concentration $\left(\left[\mathrm{Ca}^{2+}\right]_{\mathrm{i}}\right.$ ) after resact stimulation (arrow). Signals were recorded with the fluorescent indicators di-8-ANEPPS $\left(\mathrm{V}_{\mathrm{m}}\right), \operatorname{BCECF}\left(\mathrm{pH}_{\mathrm{i}}\right)$, or Fluo-4 $\left(\mathrm{Ca}^{2+}\right)$ using the stopped-flow technique. Adapted from [6].

Binding of chemoattractant molecules to a chemoreceptor located along the sperm flagellum activates a cellular signalling pathway. The chemoreceptor belongs to the family of guanylate cyclases (GC), which synthesize the cellular messenger $3^{\prime} 5^{\prime}$ cyclic guanosine monophosphate (cGMP) (Fig. 2(a)) [15,16]. In turn, cGMP opens $\mathrm{K}^{+}$-selective cyclic nucleotide-gated channels (CNGK) and $\mathrm{K}^{+}$ions leave the cell [17-19]. The ensuing hyperpolarization - the membrane potential $\left(\mathrm{V}_{\mathrm{m}}\right)$ at rest is about -45 to $-50 \mathrm{mV}$ - evokes a small intracellular alkalization via a sperm-specific $\mathrm{Na}^{+} / \mathrm{H}^{+}$exchanger (sNHE) (Fig. 2(b, c)) [5,20-22]. The alkalization shifts the voltage dependence of a sperm-specific $\mathrm{Ca}^{2+}$ channel (CatSper, cation channel of sperm) and, thereby, primes CatSper channels to open during the return to resting $\mathrm{V}_{\mathrm{m}}$ initiated by a hyperpolarization-activated and cyclic nucleotide-gated ( $\mathrm{HCN})$ channel that carries an inward $\mathrm{Na}^{+}$current $[5,23]$. A rise of $\mathrm{Ca}^{2+}$ modulates the flagellar beat. Recovery from stimulation is accomplished by a $\mathrm{Na}^{+} / \mathrm{Ca}^{2+} / \mathrm{K}^{+}$exchanger (NCKX) and a $\mathrm{Ca}^{2+}$-ATPase (PMCA) that restore the intracellular $\mathrm{Ca}^{2+}$ concentration $\left(\left[\mathrm{Ca}^{2+}\right]_{\mathrm{i}}\right)$, and a phosphodiesterase (PDE) that breaks down cGMP [24-26]. 
A fascinating feature of sea urchin sperm is that a single chemoattractant molecule can elicit a $\mathrm{Ca}^{2+}$ response [15]. Such an elementary $\mathrm{Ca}^{2+}$ response involves (1) the synthesis of about 11-45 cGMP molecules [4,17]; (2) a change in intracellular proton concentration $\left(\mathrm{pH}_{\mathrm{i}}\right)$ of about 0.01 units [5]; and (3) a $\mathrm{V}_{\mathrm{m}}$ response of about $2 \mathrm{mV}[18]$. Several mechanisms have been proposed to explain ultrasensitivity of cells. These concepts largely originate from the study of signalling in bacteria, photoreceptors, and olfactory neurons. Mechanisms that endow cells with high sensitivity include (a) lattices of highly cooperative chemoreceptors in bacteria [27-31]; (b) cascades of enzymatic reactions with high multi-stage gain [32-34]; (c) local signalling by supramolecular complexes [35-37]; and (d) restricted diffusion of cellular messengers in confined cellular sub-compartments $[38,39]$. It will become clear from the discussion of each signalling step below, that sperm by and large do not rely on any one of these mechanisms to achieve single-molecule sensitivity.

\subsection{The chemoattractant receptor}

The membrane-spanning receptor GC is composed of three domains: an extracellular domain that binds the chemoattractant, a short segment that spans the membrane, and an intracellular catalytic domain that synthesizes cGMP. Single-molecule sensitivity requires a high capture efficacy of the chemoattractant. The flagellum harbours about 300,000 GC copies at a density of 9,500 GC molecules $/ \mu \mathrm{m}^{2}[4]$. In fact, the GC rivals with rhodopsin in photoreceptors (20,000-45,000 rhodopsin molecules $\left./ \mu \mathrm{m}^{2}\right)[40,41]$ as one of the most densely packed membrane receptors.

What determines the precision by which sperm count molecules? Chemoattractants randomly impinging on the cell surface cause "molecule noise" that limits the precision by which sperm gauge the chemoattractant concentration. A measure of the precision of sensing is the uncertainty $\delta c / c$, that is the incremental increase $\delta c$ around a mean concentration $c$; only if $\delta c / c$ is sufficiently high, a binding event can be distinguished from molecule noise. If we consider a sperm cell as an absorbing sphere covered with surface receptors, the uncertainty $\delta c / c$ of measuring a concentration $c$ is given by

$$
\delta c / c=\left(N_{R} s D c t\right)^{-1 / 2},
$$

wherein $N_{R}$ is the number of the receptors, $s$ is the effective radius of the binding site, $D$ is the diffusion constant of the chemoattractant, and $t$ is the sampling time [42]. We calculated $\delta c / c$ using the following parameters: $N_{R}=3 \cdot 10^{5}$ receptors [4], $D_{\text {resact }}=2.4 \cdot 10^{-6} \mathrm{~cm}^{2} \mathrm{~s}^{-1}[14]$, and $\tau=0.5 \mathrm{~s}[14,15]$. The effective radius $s$ of the binding site is not known. Therefore, we used as upper and lower limits the radius of the extracellular GC domain $(2.65 \mathrm{~nm})$ or the radius of the resact peptide $(0.65 \mathrm{~nm})$, respectively. At concentrations as low as $c=1 \mathrm{pM}$ resact (when only a few molecules per second are impinging on the flagellum), the uncertainty $\delta c / c$ to count molecules is 13-27\%. For an ellipsoid-shaped flagellum (half-axis $a=25 \mu \mathrm{m}$ and $b=$ $0.125 \mu \mathrm{m}$; [43]), on average 3.5 resact molecules are impinging during a sampling time of $0.5 \mathrm{~s}$. This exercise illustrates that, at very low resact concentrations, A. punctulata sperm in fact can count individual binding events, i.e., operate at the physical limit. The high GC density is beneficial for a second reason. In the Berg-Purcell model [42], receptors can be reused within a few milliseconds after clearance of the binding site from ligands. However, the high ligand affinity of the GC in the sub-nanomolar range prevents receptors from becoming cleared quickly; consequently, on their voyage to the egg, sperm suffer a continuous loss of vacant or functional receptors. In comparison, bacteria and amoebae operate at nano- to micromolar chemoattractant concentrations, ligands dissociate quickly from receptors, and cells get by with $\sim 15,000$ receptors per cell [44-46]. 
GC receptors in sperm can adjust their binding affinity for the chemoattractant. At very low receptor occupancy, binding affinity is in the picomolar range $\left(\mathrm{K}_{1 / 2}=\right.$ $90 \mathrm{pM}$ ) [4]. Thus, high capture efficacy is achieved by combining an extraordinary high GC density and high ligand affinity. At higher receptor occupancy, the GC affinity is lower $\left(\mathrm{K}_{1 / 2}=0.65 \mathrm{nM}\right)$ [4]. In fact, chemoattractant binding spans six orders of magnitude [4]; the broad operational range might involve negative cooperativity among GC subunits (the receptor is composed of several subunits), negative cellular feedback, or a combination of both. Whatever the mechanisms might be, the affinity adjustment ensures that, at high chemoattractant concentrations prevailing near the egg, vacant receptors are still available.

Because of the high binding affinity, the dwell time of the ligand at the receptor is of the order of many seconds to minutes [2]. Considering that sperm sample the chemoattractant concentration at least once every second, the long dwell time necessitates a mechanism of receptor inactivation. The lifetime of the active receptor $\mathrm{GC}^{*}$ is set by dephosphorylation: at rest, six conserved serine residues carry phosphate groups that are removed upon chemoattractant binding $[4,47,48]$. Several features suggest that the GC itself catalyses the dephosphorylation reaction - a mechanism called auto-dephosphorylation [4]. Stepwise GC* inactivation by successive auto-dephosphorylation might allow for precise lifetime control and, thereby, could reduce "molecule noise" that limits the precision of gradient sensing. For rhodopsin, the visual pigment in photoreceptors, stepwise inactivation by two phosphorylation steps and "capping" of phosphorylated rhodopsin by a "stop" protein has been proposed to control its lifetime and, thereby, reduce photon noise [49-51]. However, uniform single-photon responses also involve other mechanisms, including $\mathrm{Ca}^{2+}$ feedback [52-54].

The turnover number of an active $\mathrm{GC}^{*}$ molecule is about $72 \mathrm{cGMP}$ molecules $\mathrm{s}^{-1}$ [4]. During its lifetime of ca. $150 \mathrm{~ms}$, the $\mathrm{GC}^{*}$ synthesizes about 11-45 cGMP molecules [4,17]. For comparison, in photoreceptors, which also use a cGMP-signalling pathway, a single photon stimulates the hydrolysis of 2,000 to 72,000 cGMP molecules depending on the species [54,55]. Thus, at this stage of signalling, the amplification in photoreceptors is several orders of magnitude larger.

\subsection{The CNGK channel}

cGMP opens cyclic nucleotide-gated (CNGK) $\mathrm{K}^{+}$channels and the cell hyperpolarizes, that is, the membrane voltage becomes more negative, because $\mathrm{K}^{+}$ions leave the cell via the CNGK channel [17-19]. The flagellum harbours about 12,000 copies of the CNGK channel (one copy per 25 GC copies) [4]. The density (about 350 CNGK molecules $/ \mu \mathrm{m}^{2}$ ) is similar to that of CNG channels in rod photoreceptors $[56,57]$. For a signalling complex to be effective, its components must exist in similar molar quantities. Therefore, the high stoichiometric ratio of GC:CNGK argues against receptor and channel forming a supramolecular signalling complex by direct protein-protein interaction.

The sperm CNGK channel is exquisitely cGMP sensitive $\left(\mathrm{K}_{1 / 2}=26 \mathrm{nM}\right)$, and it opens upon binding of a single cGMP molecule [17]. In contrast, the non-selective CNG channel of rod photoreceptors is about 1000-fold less sensitive [58] and opens upon cooperative binding of at least two cGMP molecules [59]. Eleven to 45 cGMP molecules, required for a single-molecule response, increase the cGMP concentration in the flagellum by about $11-45 \mathrm{nM}$ (geometric volume about 1.6 femtoliters). The few cGMP molecules can bind to 12,000 CNGK channels. Therefore, in the singlemolecule regime, when only few cGMP molecules are produced, the probability that 
2-4 cGMP molecules occupy the CNGK channel at the same time would be vanishingly small. Thus, cooperative activation of the CNGK channel by several cGMP molecules would impair rather than enhance sensitivity. Thus, the CNGK channel has evolved a cGMP affinity and activation mechanism tuned to extremely low ligand concentrations. Because of the large input resistance of sperm ( current passing through a single open CNGK channel might suffice to produce an elementary voltage response of $2 \mathrm{mV}$. For comparison, a single-photon response of $1 \mathrm{mV}$ in rod photoreceptors involves closure of several hundreds of CNG channels [57].

\subsection{The CatSper $\mathrm{Ca}^{2+}$ channel}

CatSper is one of the most complex voltage-gated ion channels. Similar to mammalian sperm [60], CatSper in the sea urchin A. punctulata comprises four homologous subunits (CatSper 1-4) and at least three auxiliary subunits (CatSper $\beta$, CatSper $\gamma$, and CatSper $\delta$ ) [5]; however, the mechanism of activation in mammals and sea urchin is different. In human sperm, CatSper is activated by the female hormone progesterone $[61,62]$ through an unusual endocannabinoid mechanism [63]. In sea urchin sperm, CatSper is activated by an allosteric mechanism that might serve as a "switch". The alkalization brought about by the activation of the sNHE exchanger during hyperpolarization shifts the voltage dependence of CatSper activation to more negative values, thus allowing opening and closure of CatSper by $\mathrm{V}_{\mathrm{m}}$ in the physiological range; the dependence of CatSper opening on proton concentration (i.e., $\mathrm{pH}_{\mathrm{i}}$ ) is exceptionally steep (Hill coefficient of about 11) [5]. The high cooperativity of control by $\mathrm{pH}_{\mathrm{i}}$ permits CatSper to faithfully transduce the elementary changes in $\mathrm{pH}_{\mathrm{i}}$ and $\mathrm{V}_{\mathrm{m}}$ into a $\mathrm{Ca}^{2+}$ signal.

\subsection{Other molecules of the signalling pathway: sNHE, HCN, sAC, and PDE}

There are other molecules for which we know much less how they quantitatively integrate into this signalling scheme. The sNHE is unique and still enigmatic. It encompasses a classic transmembrane exchanger domain and, surprisingly, a prototypical voltage-sensor domain (VSD) of voltage-gated ion channels and a cyclic nucleotidebinding domain (CNBD) [22]. The functions of the VSD and the CNBD are unknown, not least because the sNHE has resisted functional expression in a heterologous cell system.

$\mathrm{HCN}$ channels carry a depolarizing $\mathrm{Na}^{+}$inward current that resists further hyperpolarization. Thus, the HCN channel might help to recover from chemoattractant stimulation. In photoreceptors, HCN channels blunt the hyperpolarizing light response and thereby, $\mathrm{HCN}$ channels expand the dynamic range of light sensitivity. Through a similar mechanism in sperm, HCN channels might prevent that the reversal potential $\mathrm{V}_{\text {rev }}$ of the CNGK channel is reached prematurely and, thereby, the HCN channel might extend the concentration range of chemoattractant sensing. Finally, HCN channels control electrical oscillations in neurons and the heart $[64,65]$. Similarly, HCN channels in sperm might tune $\mathrm{Ca}^{2+}$ oscillations to periodic changes in chemoattractant concentration. This needs to be studied by future work.

The role a soluble adenylyl cyclase (sAC) - an enzyme that synthesizes cAMP in sea urchin sperm is still enigmatic: cAMP rises upon stimulation of sperm with the chemoattractant, and it might modulate the activity of cAMP-sensitive HCN channels [23]. The PDE that hydrolyses cGMP, and therefore shuts down the chemotactic signalling cascade, is related to the PDE5 isoform, the Viagra-sensitive PDE of mammalian cells; however, its mechanisms of activation and regulation are largely unknown. The interplay between sAC, NHE, HCN, and PDE is largely unknown and requires future studies. 


\subsection{Summary}

In conclusion, to achieve single-molecule sensitivity, sperm neither rely on supramolecular assemblies of cooperative receptors and ion channels nor on high-gain enzymatic amplification. Instead, sperm rely on the exquisite sensitivity of CNGK and CatSper channels to cGMP and $\mathrm{pH}_{\mathrm{i}}$, respectively. Of note, if we assume that changes in membrane potential propagate along the flagellum similar as they do in cables and neuronal axons [66], from the input resistance [67] and the membrane capacitance of sperm, it can be predicted that the hyperpolarization initially produced in the vicinity of a receptor, should spread along the flagellum within about a millisecond timescale and affect all voltage-dependent molecules, for example sNHE exchangers and CatSper channels; this mechanism can be considered as another amplification step.

How common is this pathway? Molecular components and biochemical reactions of the Arbacia signalling pathway have also been identified in other sea urchin species [68-70]. Sperm of the seafish Asterias amurensis also use a cGMP-signalling pathway for chemotaxis [71-73]. Additionally, genomes of several other marine invertebrates and fish host a CNGK gene [74]. Finally, many vertebrates - including all mammals - and some marine invertebrates host the CatSper gene [75].

\section{Sperm navigation - a strategy of periodic motion}

\subsection{Sperm navigation in 2D}

For the study of sperm chemotaxis, the development of caged compounds has been key. Caged compounds represent biological molecules that have been rendered inactive by covalent chemical modification. The caged form can be cleaved by UV light irradiation (photolytic reaction) to yield the active molecule and the caging group. Caged compounds are elegant tools to trigger and monitor cellular and biochemical reactions with spatio-temporal precision in a non-invasive manner. For our studies, we use caged derivatives of the chemoattractant resact and of the second messenger cGMP $[8,76,77]$. A chemical gradient is rapidly sculptured by UV light irradiation of a sperm suspension containing caged resact; the ensuing behavioural response can be followed under the microscope.

Due to technical limitations, sperm chemotaxis has primarily been studied in two dimensions (2D). While swimming in shallow observation chambers, sperm are attracted to the glass/water interface by hydrodynamic forces [78-80], which facilitates the observation of cell movement in the focal plane (Fig. 3(a)) [73]. While swimming in a chemical gradient of resact, sperm alternate between episodes of higher and lower asymmetry of the flagellar beat. As a result, sperm move on drifting circles up the gradient. Inspired by this periodic swimming pattern, a theory was developed that captures the essence of chemotactic navigation $[2,81]$. A cellular signalling system transforms the periodic stimulation $s(t)$ (chemoattractant binding) into a periodic intracellular signal $i(t)$ that in turn produces a periodic modulation of the swimming path curvature $\kappa(t)$. The resulting looping path guides sperm up or down the gradient, depending on the phase relation between $s(t)$ and $\kappa(t)$ (Fig. 3(b,c)). The phase relation is determined by the latency of the $\mathrm{Ca}^{2+}$ response and the ensuing motility response. Many cells and organisms also follow gradients of chemical or physical cues on periodic paths [82]. The sensory modalities used for navigation are as diverse as phototaxis, thermosensation, taste, olfaction, and electroreception; the organisms and cells include the nematode C. elegans, larvae from Drosophila and Platynereis, primordial germ cells of zebrafish, the alga Chlamydomonas, protists, and even some bacteria [83-88]. 

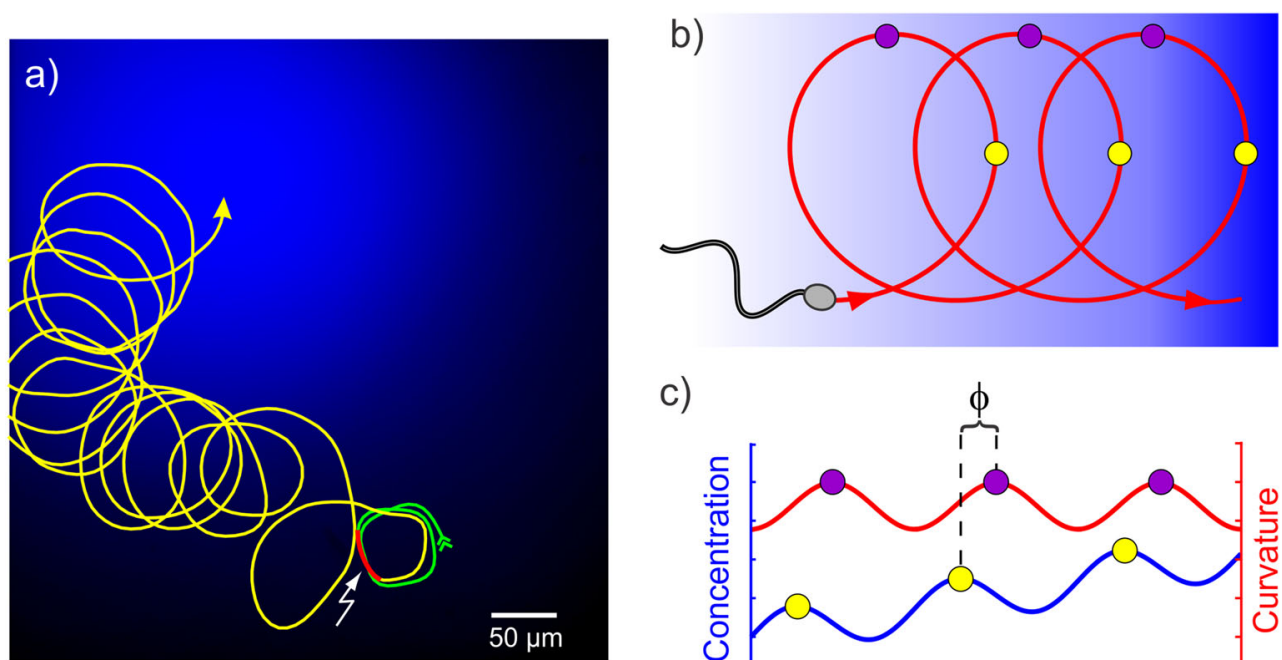

c)

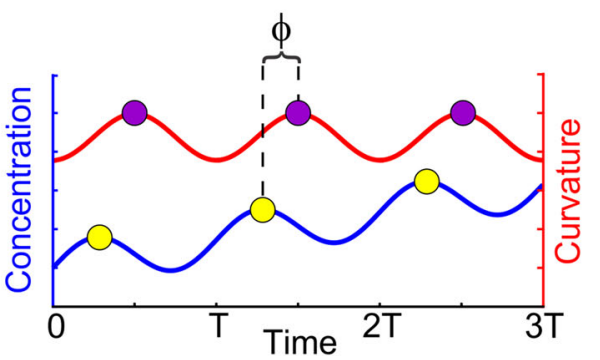

Fig. 3. (a) Swimming path of sea urchin sperm in a chemoattractant gradient. Before stimulation, sperm swim on circles (green) at the glass/water interface of a shallow observation chamber. Upon release of the chemoattractant from its caged derivative (profile of the UV light shown in blue shades), the path curvature begins oscillating and sperm swim on drifting circles up the chemical gradient (yellow). The photolysis duration is shown in red. (b) Diagram of a sperm cell navigating in a gradient of resact (blue). While swimming along a circular path, the cell is exposed to a concentration stimulus that varies periodically with the frequency of circular swimming. The local maximum is indicated by yellow dots. (c) The periodic modulation of the stimulus concentration (blue trace) encodes the spatial information about the chemical gradient. A chemotactic signalling pathway in the sperm flagellum transduces the periodic stimulus into a periodic steering response that regulates the swimming path curvature. Generically, a periodic concentration input (blue trace) produces a periodic modulation output of the path curvature (red trace). The phase difference $\phi$ between the local maxima of the concentration (yellow dots on blue trace) and the local maxima of the path curvature (purple dots on red trace) determines the direction of chemotactic drift. Adapted from $[2,6]$.

\subsection{The link between sperm motility and chemotactic signalling}

Previous studies have shown that extracellular $\mathrm{Ca}^{2+}$ is essential for sperm chemotaxis [12]. Furthermore, photolysis of caged cGMP inside sperm elicits robust $\mathrm{Ca}^{2+}$ and motor responses that are abolished at low extracellular $\mathrm{Ca}^{2+}[15]$. Thus, sperm use a signalling pathway that ultimately translates chemoattractant binding into a rise of $\left[\mathrm{Ca}^{2+}\right]_{\mathrm{i}}$. To study the link between $\mathrm{Ca}^{2+}$ and swimming behaviour, a stroboscopic technique was developed to record $\mathrm{Ca}^{2+}$ signals from rapidly moving sperm navigating in a chemical gradient [73].

\subsubsection{Sperm navigation is controlled by the time derivative of $\left[\mathrm{Ca}^{2+}\right]_{\mathbf{i}}$}

Initial studies in sperm with a leaky cell membrane have shown that $\left[\mathrm{Ca}^{2+}\right]$ affects the asymmetry of the flagellar beat [89-92]. Moreover, during chemotaxis, sperm produce $\mathrm{Ca}^{2+}$ oscillations in the flagellum $[7,13,73]$. These two observations lead 


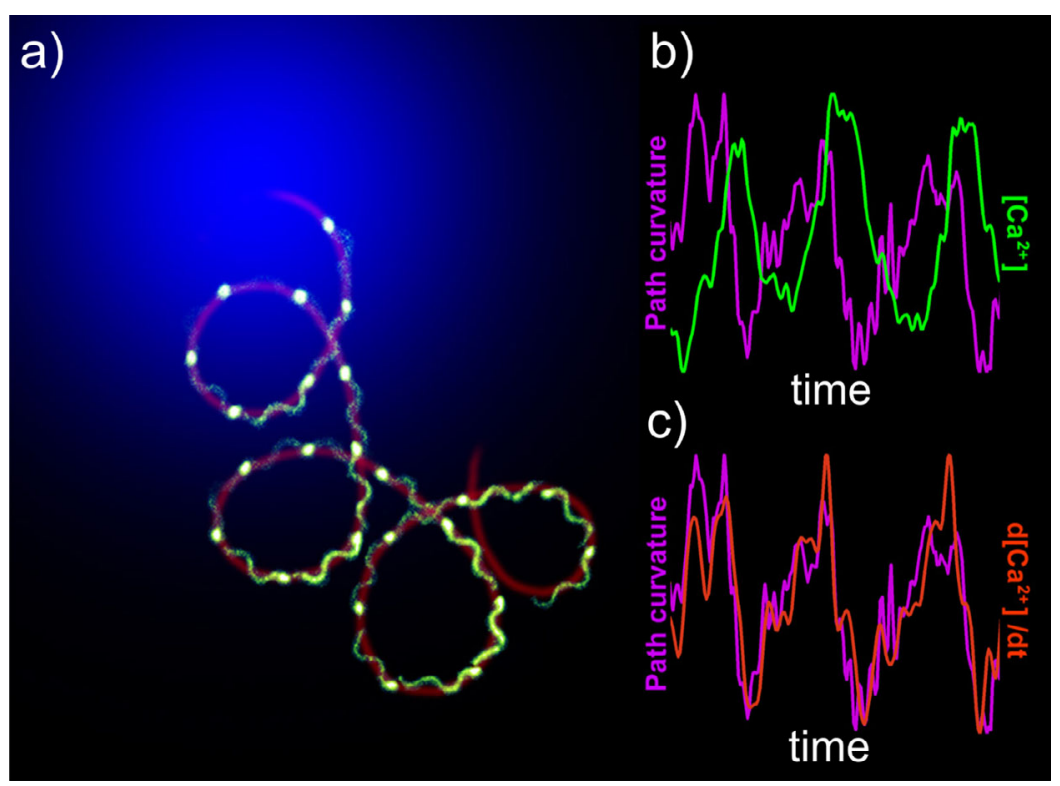

Fig. 4. Time derivative of $\mathrm{Ca}^{2+}$ concentration controls curvature of the swimming path. (a) Recording of $\mathrm{Ca}^{2+}$ in a sperm cell that navigates in a gradient of chemoattractant (profile of the UV light shown in blue shades). The cell is loaded with a $\mathrm{Ca}^{2+}$ indicator. The variation of the green fluorescence reflects oscillations of $\left[\mathrm{Ca}^{2+}\right]_{\mathrm{i}}$ (green). The average swimming path is shown in dark red. (b) Comparison of changes in $\left[\mathrm{Ca}^{2+}\right]_{\mathrm{i}}$ (green) and curvature of the swimming path (violet). (c) Comparison of the time derivative of $\left[\mathrm{Ca}^{2+}\right]_{\mathrm{i}}$ (red) and the curvature of the swimming path (violet).

to the view that $\mathrm{Ca}^{2+}$ oscillations entrained by the periodic stimulation produce alternating periods of asymmetrical beating at high $\left[\mathrm{Ca}^{2+}\right]_{i}$ and symmetrical beating at low $\left[\mathrm{Ca}^{2+}\right]_{\mathrm{i}}$. A corollary of this notion is that for high and low path curvature $\kappa$, the $\left[\mathrm{Ca}^{2+}\right]_{\mathrm{i}}$ should be high and low, respectively. However, it was noted that high $\mathrm{Ca}^{2+}$ levels persist during straight swimming, i.e. when the path curvature is low $[9,13,73,93,94]$, challenging the view that $\kappa$ is directly set by $\left[\mathrm{Ca}^{2+}\right]_{\mathrm{i}}$. To resolve this conundrum, we determined the signal transfer function between $\left[\mathrm{Ca}^{2+}\right]_{\mathrm{i}}$ (input) and $\kappa$ (output) [7] (Fig. 4). Surprisingly, it is the rate of change $\mathrm{d}\left[\mathrm{Ca}^{2+}\right]_{\mathrm{i}} / \mathrm{d} t$ rather than absolute $\left[\mathrm{Ca}^{2+}\right]_{\mathrm{i}}$ that modulates $\kappa$. To a first approximation, $\mathrm{d}\left[\mathrm{Ca}^{2+}\right]_{\mathrm{i}} / \mathrm{d} t$ and the path curvature $\kappa$ are linearly related (Fig. 4(c)):

$$
\kappa \approx \kappa_{0}+A \frac{\mathrm{d}\left[\mathrm{Ca}^{2+}\right]}{\mathrm{d} t}
$$

wherein $\kappa_{0}$ and $A$ are constants of the linear fit.

Thus, for a given $\mathrm{Ca}^{2+}$ signal, the path curvature and the swimming path can be predicted with fair precision. Simulations using various waveforms of the $\mathrm{Ca}^{2+}$ signal reproduce the richness of sperm swimming patterns - from looping paths characterized by sharp "turns" and wide "running" arcs to smoothly drifting circles (Fig. 5(a-c)). Specifically, steep and long $\mathrm{Ca}^{2+}$ surges, probably evoked by strong stimulation in steep gradients, produce sharp turns and long runs. For this swimming pattern, high spatial resolution is compromised in favor of making headway. Smaller $\mathrm{Ca}^{2+}$ signals, probably evoked in shallower gradients, produce slowly drifting circles, that is, the incremental advance per cycle period is smaller than the circle diameter, thus providing a mechanism by which sperm might enhance their spatial resolution and sensitivity in shallow gradients. 
a)

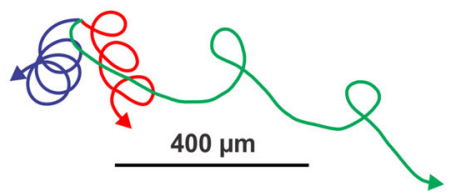

b)

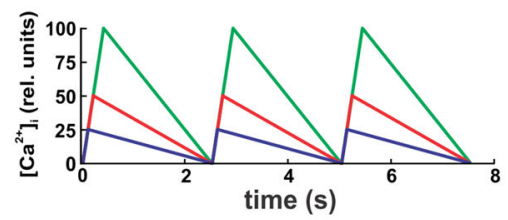

c)

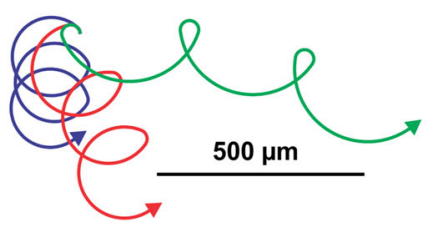

d)

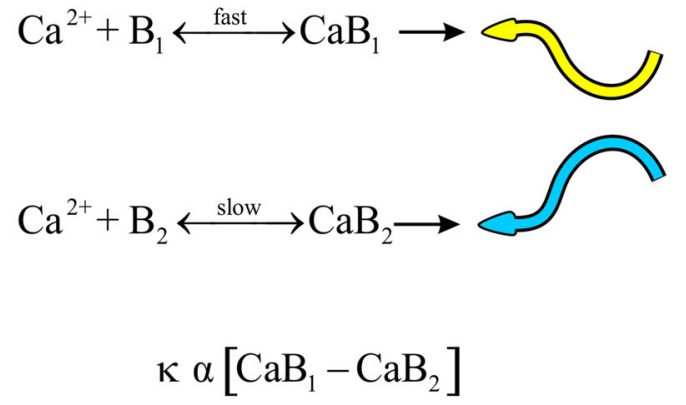

Fig. 5. Numerical simulations reproduce the wealth of swimming paths of sperm from marine invertebrates. (a) Three representative swimming paths recorded from single sperm cells. (b) $\mathrm{Ca}^{2+}$ signals used for the numerical reconstruction shown in part (c). (c) Swimming paths derived from the $\mathrm{Ca}^{2+}$ signals shown in part (b). The experimental and simulated swimming paths are very similar. (d) The "chemical differentiator" model. $\mathrm{Ca}^{2+}$ binds to two proteins. One binding reaction is fast (binding to $\mathrm{B}_{1}$ ), whereas the other reaction is slow (binding to $\mathrm{B}_{2}$ ). The two binding events promote bending of the tail in opposite directions. The overall flagellar bending, and thus $\kappa$, is proportional to the difference of $\mathrm{B}_{1}$ and $\mathrm{B}_{2}$ occupancy. Adapted from $[6,7]$.

When cells sample a concentration over some time $t$, rapid fluctuations in the chemoattractant field are averaged out. In the language of signal processing, the chemotactic input is low-pass filtered, i.e. cells only perceive a "smoothed" concentration landscape. Cells and organisms use several mechanisms to extend the operational range to sensory stimuli input, a process generally referred to as adaptation or adjustment of sensitivity [95]. When cells adapt to the stimulus, slow modulations of the mean background concentration are filtered. Thus, adaptation represents a high-pass filter. The transfer function between the $\mathrm{Ca}^{2+}$ signal and the curvature $\kappa$ (Eq. (3)) corresponds to an adapting mechanism that acts as a high-pass filter. The combination of a low-pass filter (temporal integration) and a high-pass filter (adaptation) is known as a band-pass filter. Such filtering is well suited to detect periodic modulations of the chemoattractant concentration during chemotaxis. We speculate that the signalling system of sperm is thus tuned to the $\sim 1 \mathrm{~Hz}$ frequency of circular 2D swimming. Another example for such filtering is provided by phototaxis of Chlamydomonas that relies on periodic light stimuli that result from a body rotation at $2 \mathrm{~Hz}$ [96]. The photoreceptor current, that eventually controls phototaxis, is maximal when cells are light-stimulated with frequencies similar to the body rotation frequency. In other words, phototactic signalling too serves as band-pass filter.

\subsubsection{A chemical differentiator model}

The relationship between $\left[\mathrm{Ca}^{2+}\right]_{\mathrm{i}}$ and $\kappa$ represents a mechanism of adaptation by which the cell responds only to rapid changes in $\left[\mathrm{Ca}^{2+}\right]_{\mathrm{i}}$. Despite the simple relation 
a)

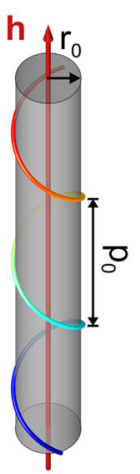

b)

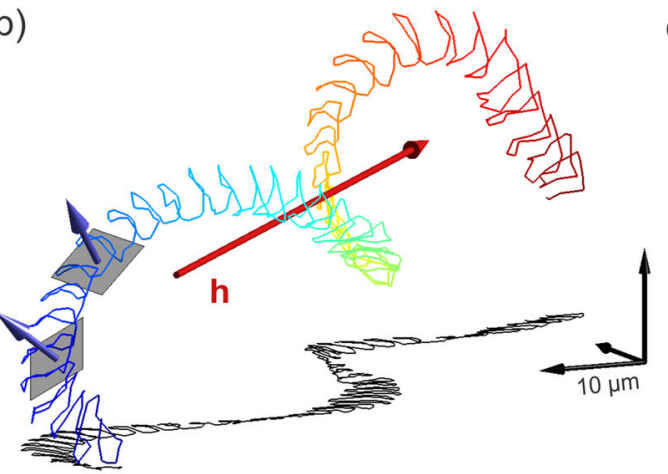

c)

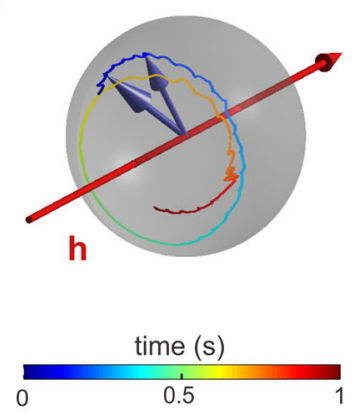

Fig. 6. Freely swimming sperm navigate along helical paths. (a) Diagram showing the average swimming path (1-sec duration) of unstimulated sperm (see colored bar). Radius $\mathrm{r}_{0}=8.4 \mu \mathrm{m}$ and pitch $\mathrm{p}_{0}=47.6 \mu \mathrm{m}$ are drawn to scale. (b) Holographic reconstruction of the $3 \mathrm{D}$ swimming path far from walls. Head wiggling was used to determine the beating plane orientation. (c) The vector normal to the beating plane (blue arrows) precesses around the helical axis (h, red arrow) with fixed inclination, describing a circle on the surface of a unit sphere. Vectors are not to scale. Reproduced from [8].

between $\mathrm{d}\left[\mathrm{Ca}^{2+}\right] / \mathrm{d} t$ and $\kappa($ Eq. (3)), it is unclear how sperm perform such a computational operation. Cilia represent a unique $\mathrm{Ca}^{2+}$ signalling compartment $[97,98]$ and in the axoneme of Chlamydomonas, about 27 proteins have been identified that carry an "EF-hand", a structural $\mathrm{Ca}^{2+}$-binding motif shared by many proteins [99]. Calmodulin (CaM), a key $\mathrm{Ca}^{2+}$ sensor in cilia, is associated with the radial spoke stalk and the central pair, and several CaM-binding proteins have been identified [100-102]. Thus, it is likely that $\mathrm{Ca}^{2+}$-binding proteins are involved in "computing" the time derivative of $\left[\mathrm{Ca}^{2+}\right]_{\mathrm{i}}$. A "chemical" differentiator model is built from either two $\mathrm{Ca}^{2+}$-binding proteins (or a single $\mathrm{Ca}^{2+}$-binding protein with two binding sites) that translate changes in $\left[\mathrm{Ca}^{2+}\right]_{\mathrm{i}}$ into flagellar bending (Fig. $5(\mathrm{~d})$ ). The model encompasses two simple features. First, upon binding of one $\mathrm{Ca}^{2+}$ ion, the flagellum beats in one direction; upon binding of a second $\mathrm{Ca}^{2+}$ ion, the flagellum beats to the opposite direction. If binding of the second $\mathrm{Ca}^{2+}$ ion is delayed, the total flagellar bending will follow $\mathrm{d}\left[\mathrm{Ca}^{2+}\right]_{\mathrm{i}} / \mathrm{d} t$. This model can be easily generalized to other cellular messengers and other cellular responses (see appendix for a full analytical solution of the model and the approximations involved). Even on an organismic level, a similar mechanism exists. During chemotaxis, C. elegans responds to temporal changes of salt concentration. The response is controlled by two chemosensory neurons that, like in the chemical differentiator model, elicit opposite turning/run behaviours of the animal [103].

Using numerical methods and resistive-force theory, we calculated the swimming path of sperm for different flagellar waveforms. Sperm models with positive mean flagellar curvature and a small flagellar twist swam along helical swimming paths (Fig. 7(a)). Without twist, a planar circular swimming path is obtained (equivalent to a helix with zero pitch; Fig. 7(b)); with zero mean flagellar curvature, the swimming path resembles a twisted ribbon (equivalent to a helix with zero radius; Fig. $7(\mathrm{c})$ ). Such a swimming pattern has been observed for human and horse sperm [82]. Future studies need to experimentally determine the shape of the sea urchin sperm flagellum while swimming in $3 \mathrm{D}$. 
a)
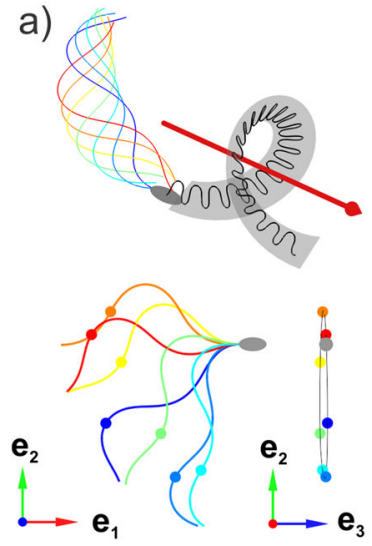

b)
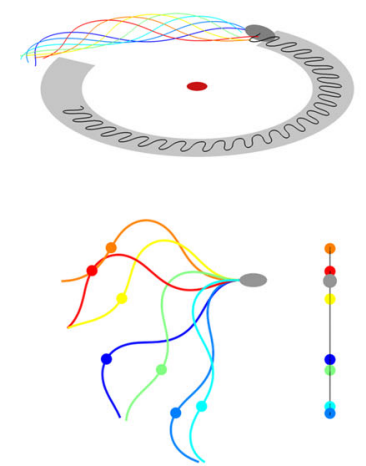

c)

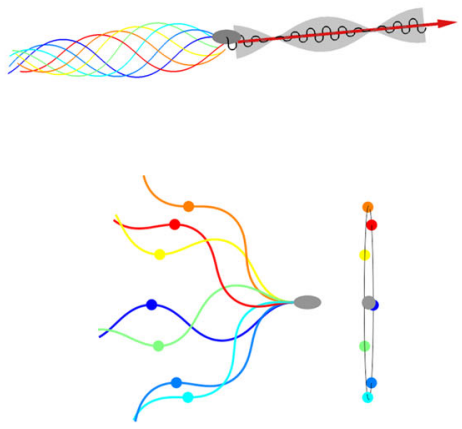

Fig. 7. Simulations of sperm swimming for three models of different flagellar waveforms. Swimming path (top) and sequence of flagellar shapes (bottom) during one beat cycle aligned at the sperm head (grey) with a coloured reference point on the flagellum (left: top view; right: side view). (a) A sperm model with a flagellar beat twisted and asymmetric (mean curvature $>0$ ) swims along helical paths (helix axis shown in red). (b) Model with a planar flagellar beat; the cell swims along a planar circular path - which can be regarded as a helix with zero pitch. (c) Model with a symmetric twisted flagellar beat leads to swimming along ribbons - which can be regarded as a helix with zero radius. Adapted from [8].

\subsection{Sperm navigation in 3D}

Although studies of 2D motility provided invaluable insight into chemotaxis, in the ocean, sperm swim unrestricted in 3D. Using holographic techniques, we unveiled the $3 \mathrm{D}$ navigation strategy of sperm in a $3 \mathrm{D}$ chemical gradient [8].

\subsubsection{Swimming freely in 3D}

Using digital inline high-speed holographic microscopy, we track sperm swimming unrestricted far away from walls. Under these conditions, sperm swim along helical paths [104,105]. The average helical path is characterized by radius $r_{0}=8.4 \pm 3.1 \mu \mathrm{m}$, pitch $p_{0}=47.6 \pm 9.1 \mu \mathrm{m}$, and helix period $T=0.38 \pm 0.07 \mathrm{~s}$ (Fig. 6(a)). The sperm head wiggles around the average path with a frequency identical to that of the flagellar beat; passive head wiggling counterbalances periodic forces generated by active flagellar bending. Using head motion as readout of the flagellar beat, we show that the flagellum beats in a plane that slowly rotates around the helix axis; a full plane rotation is achieved after completion of a helix period (Fig. 6(b,c)).

\subsubsection{Sperm navigation in a 3D chemical gradient}

The principles of chemotactic steering on a helical path were studied in 3D gradients of the chemoattractant; the gradient was established by photolysis of caged resact using a Gaussian beam of UV light. Taking into account the photochemical properties of caged resact and the diffusion coefficient of resact, the chemoattractant concentration field $c(\mathbf{r}, t)$ can be predicted at any point in space and time; thereby, swimming behaviours can be linked to the spatio-temporal pattern of the chemotactic stimulus 
a)
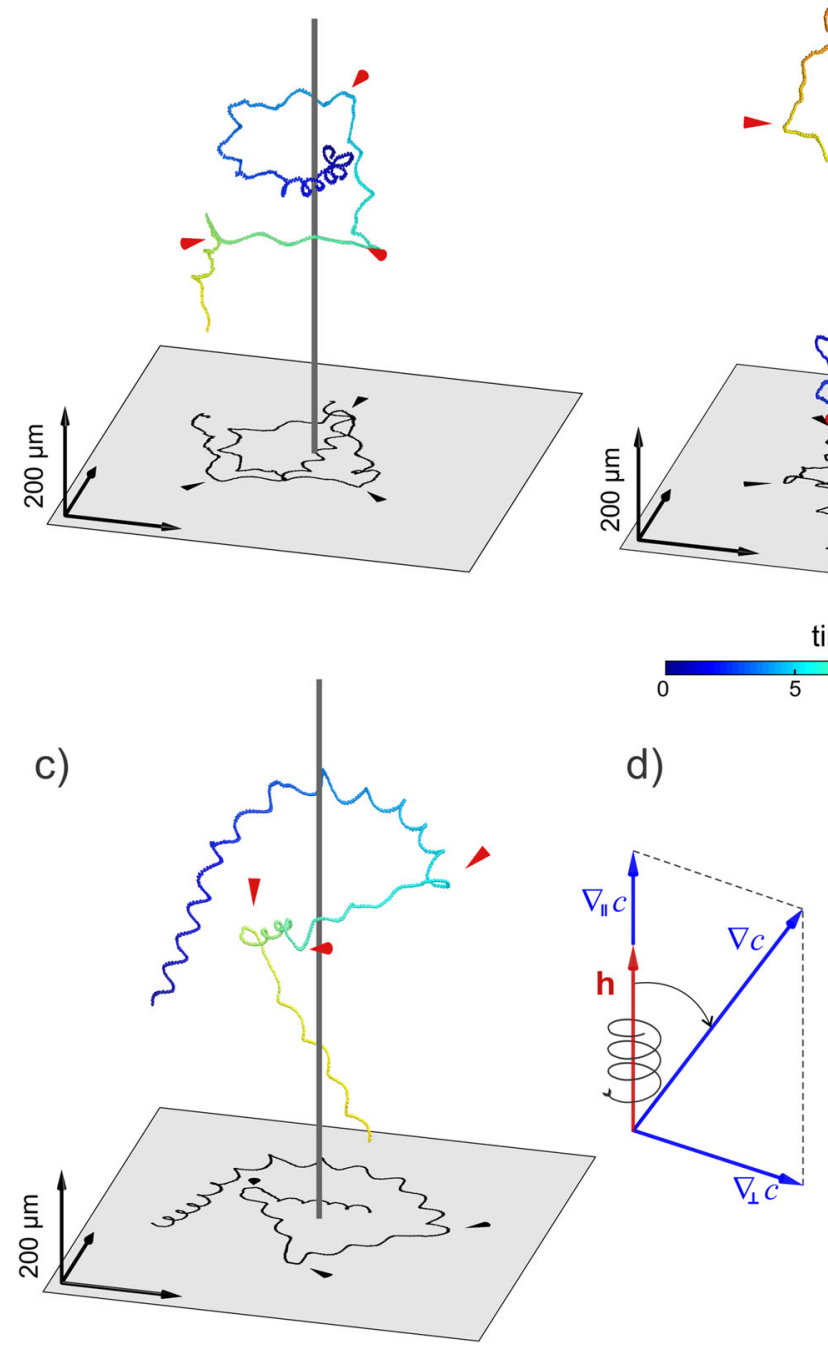

b)

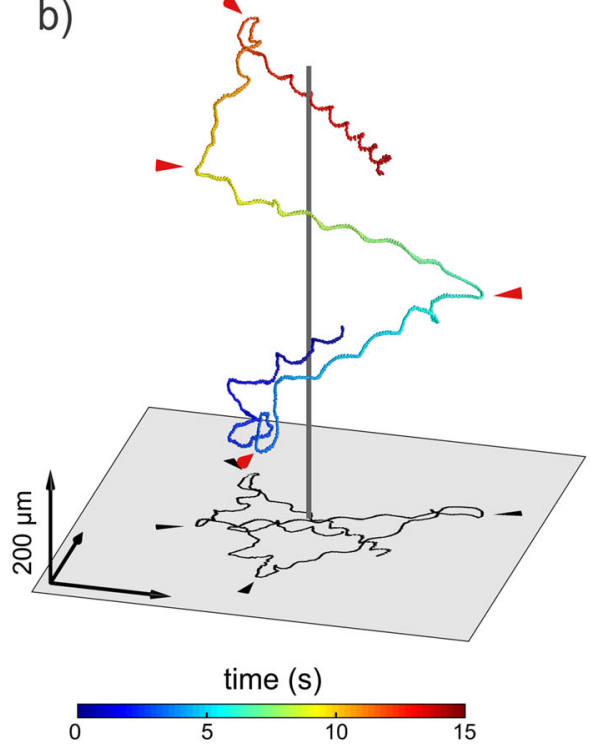

d)

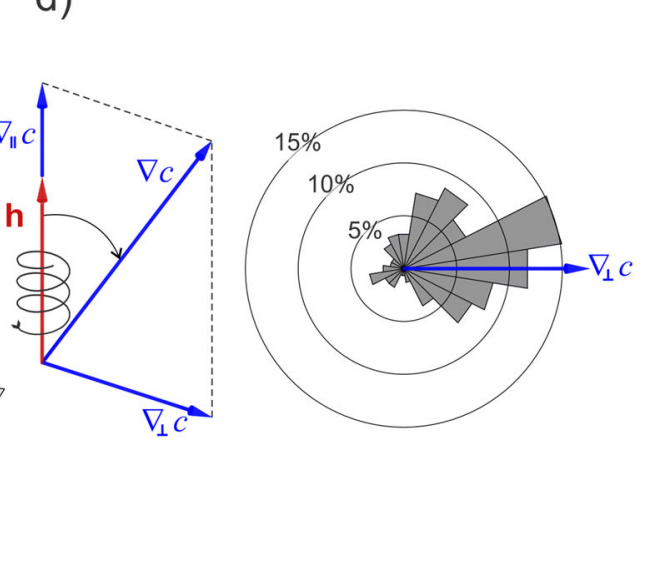

Fig. 8. Sperm chemotaxis in 3D. (a-c) Swimming paths of sperm cells swimming in a chemical gradient established by photolysis of caged chemoattractant. The concentration gradient is symmetric by rotation around the axis shown by a vertical grey line. Time is indicated in false colours along the path. Sperm display two stereotypical behaviours: smooth steady bending of the helical axis and abrupt turns (red arrowheads). (d) Left: the chemical gradient (blue) can be decomposed into components parallel $\nabla_{\|} c$ and perpendicular $\nabla_{\perp} c$ to the helical axis $(\mathbf{h}$; red). For alignment with the gradient, $\mathbf{h}$ must rotate in the direction of the perpendicular gradient component. Right: Rose plot showing the direction of $\mathbf{h}$ changes $(\mathrm{n}=10$ cells). Changes in $\mathbf{h}$ scatter around the perpendicular direction of the gradient, thus sperm steers deterministically. Adapted from [8].

(Figs. 8, 9). In a gradient, behavioural responses that adjust the swimming path range between gradual smooth alignment and abrupt turns (Figs. 8(a-c)). Irrespective of the response strength, sperm always align the helical axis with the chemical gradient (Fig. 8(d)). Comparison of chemotactic behaviour of sperm with bacterial microswimmers is illustrative. Bacteria alternate between straight swimming ("run") and tumbling episodes that randomize the swimming direction. Bacteria prolong or 
a)

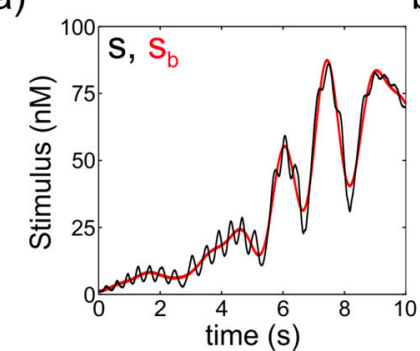

d)

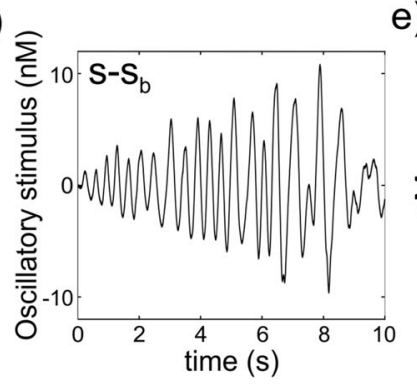

b)

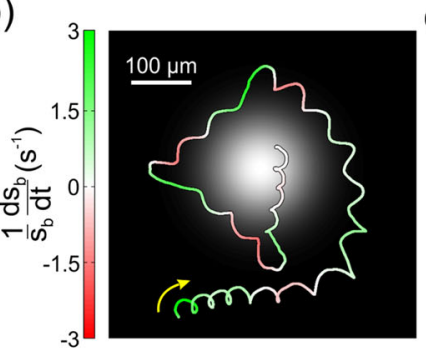

e)

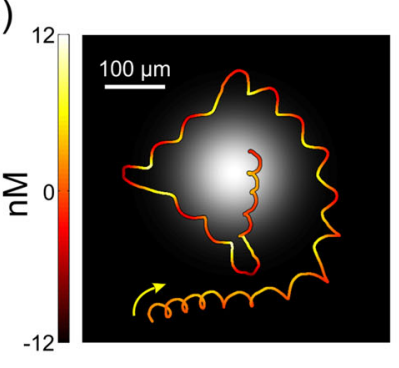

c)

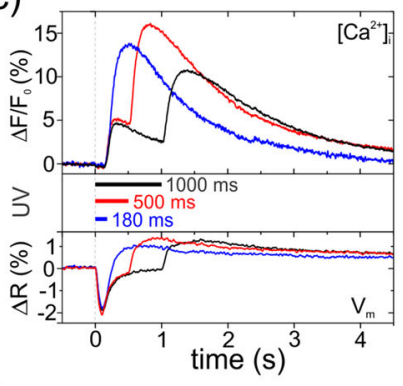

f)

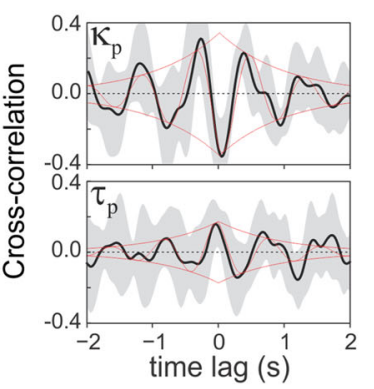

Fig. 9. Coupling between stimulus and sperm behaviours. (a) The chemoattractant stimulus encountered by the cell shown in Fig. 8(c) (black) can be decomposed into a slowly changing stimulus baseline $\left(\mathrm{s}_{b}\right.$, red) and $2 \mathrm{~Hz}$ oscillations superimposed onto the baseline. (b) The time derivative of the stimulus baseline $\left(\mathrm{d} s_{b} / \mathrm{d} t\right)$ relative to the stimulus baseline is color-coded along the path (top view shown). The profile of the UV photolyzing beam at the focal plane is shown in shades of grey. Shortly after down-gradient swimming (red), the cell turns abruptly (off response) and swims up-gradient again (green). (c) Relative changes in $\left[\mathrm{Ca}^{2+}\right]_{\mathrm{i}}\left(\Delta F / F_{0}\right.$; top) and membrane potential $\mathrm{V}_{\mathrm{m}}(\Delta R$; bottom) of sperm upon release cGMP by UV lightpulses of 180,500 , or $1000 \mathrm{~ms}$ duration. Release of cGMP results in a rapid hyperpolarization and depolarization of sperm followed by a rise of $\left[\mathrm{Ca}^{2+}\right]_{\mathrm{i}}$ (on response). When light pulses longer than the latency of the first $\mathrm{Ca}^{2+}$ response cease, a second $\mathrm{Ca}^{2+}$ signal takes place (off response). (d) Oscillatory component of the stimulus encountered by the cell. (e) The oscillatory stimulus at ca. $2 \mathrm{~Hz}$ (color-coded) results from the periodic component of helical swimming in the gradient. (f) Cross-correlations between the high-frequency stimulus and modulations of path curvature $\left(\kappa_{\mathrm{p}}\right.$; top) or torsion $\left(\tau_{\mathrm{p}}\right.$; bottom) with mean values shown in black and s.d. in grey $(n=10$ cells $)$. Thin red lines show a fitted model of phase-locked oscillations and its exponential amplitude decay. Adapted from [8].

shorten the period of straight swimming when moving up or down a chemical gradient, respectively. This strategy is referred to as "biased random walk". In contrast, sperm follow a steering strategy that is deterministic rather than random. How can we rationalize the choice of search strategy for these different cells? Small bacteria such as E.coli, undergo stochastic rotational diffusion that randomizes the swimming direction for run times longer than the characteristic diffusion time $[2,43]$. For large cells such as sperm, rotational diffusion becomes negligible. Thus, sperm swim with high directional persistence. We speculate that "biased random walk" is a strategy suitable to locate large chemoattractant plumes, whereas deterministic steering is required for finding a small target such as an egg. 


\subsubsection{Experimental validation of chemotaxis theory}

The 2D model of chemotactic steering was extrapolated to 3D swimming along helical paths [81]. Here, oscillations of path curvature $\kappa_{\mathrm{p}}$ and path torsion $\tau_{\mathrm{p}}$ entrained by the stimulus lead to chemotaxis. Moreover, the theory predicts that chemotaxis is optimal for phase relations $\phi_{\kappa}=180^{\circ}$ and $\phi_{\tau}=0^{\circ}$ between stimulus and response oscillations. This prediction is born out by experiment. We decomposed by spectral filtering the chemotactic stimulus into two components: a slow component that results from net drifting of sperm in the gradient (stimulus baseline; Fig. 9(a) red), and a rapid component that arises from the $2 \mathrm{~Hz}$ periodic component of helical swimming (oscillatory stimulus; Fig. 9(d)). Indeed, path curvature and torsion display phaselocked oscillations at the frequency of the helical periodicity with phase values of $\phi_{\kappa}=205.7^{\circ}$ and $\phi_{\tau}=-16.3^{\circ}$, similar to the optimal values predicted by theory (Fig. 9(f)).

\subsubsection{On and off responses}

How do slow changes in stimulus baseline shape the swimming path? To answer this question, we display the time derivative of the stimulus baseline along the swimming path (Fig. 9(b)). Smooth steady alignment of the helical axis with the gradient occurs when sperm swim up the gradient; when sperm swim down the gradient, abrupt corrective responses occur that involve major changes in the helix geometry. We refer to the steady alignment and the abrupt turn as on and off response, respectively. Abrupt off steering maneuvers endow sperm with the means to rapidly correct their path when veering off course or when steady helix alignment (on response) is not sufficient.

The cellular mechanisms underlying on and off responses can be readily revealed by kinetic optochemical techniques [8] (Fig. 9(c)). In short, the cellular $\mathrm{V}_{\mathrm{m}}$ and $\mathrm{Ca}^{2+}$ responses have been recorded while sperm, loaded with caged cGMP, were stimulated with pulses of photolyzing light of different length. The pulses mimic on and off stimulation: When the light is on, cGMP is continuously produced from caged cGMP and the cGMP level is expected to increase steadily, mimicking the rise of the intracellular messenger cGMP during swimming up the chemical gradient. Eventually, a steadystate balance is reached between cGMP production by light and cGMP hydrolysis by the PDE enzyme. When the light is switched off, cGMP production ceases and hydrolysis prevails, as it would be expected when stimulation declines during swimming down the chemoattractant gradient; ultimately, cGMP levels rapidly return to resting values. A brief light pulse, shorter than the latency of the $\mathrm{Ca}^{2+}$ response, produces a normal hyperpolarizing $\mathrm{V}_{\mathrm{m}}$ response followed by a $\mathrm{Ca}^{2+}$ signal. For long light pulses (i.e. prolonged "cGMP synthesis"), the decline from the hyperpolarization peak is slower and incomplete. Because CatSper channels open on membrane depolarization, the $\mathrm{Ca}^{2+}$ responses are smaller compared to the control. After the light is switched off (i.e. when cGMP production ceases), the recovery from hyperpolarization is rapidly completed, giving rise to a second large $\mathrm{Ca}^{2+}$ off response. The first smaller $\mathrm{Ca}^{2+}$ signal probably causes smooth helix bending, whereas the second $\mathrm{Ca}^{2+}$ signal elicits the brisk behavioural off response.

\section{Conclusion}

Sea urchin sperm represent a prime example of biological microswimmers that operate at the physical limit of signal detection and transduction, that is, in the realm of statistical physics. Compared to other microswimmers like bacteria, steering is 
deterministic rather than stochastic. Sperm survey the chemical landscape of attractants on long and short time scales; through a cascade of biochemical reactions, sperm translate binding events of the chemoattractant into behavioural swimming responses. Stimulus oscillations that result from the periodic component of helical swimming are translated into oscillatory motor responses that align the helical axis with the gradient in a deterministic fashion. Additionally, due to the progression of sperm along the helical path in the gradient, stimulus oscillations are superimposed onto a drifting mean stimulation level. This second stimulus component sets the strength of responses: While swimming up the gradient sperm adjust their course smoothly (on responses), whereas swimming down the gradient results in abrupt chemotactic turns (off responses). On and off responses can be attributed to characteristics of biochemical and electrical signalling. Future work along these lines probably will provide further insights regarding navigation in complex stimulus landscapes, not only for sperm, but for other cells or organisms as well. The principles outlined here might inspire the design of artificial microswimmer robots [106].

Many challenges are still ahead to understand sperm chemotaxis at all levels. A complete systems biology description of the signalling pathway is under development using logical networks [107]. This model can qualitatively reproduce the impact of pharmacological agents on signalling [108], but cannot yet account for the quantitative kinetics of intracellular signals. Furthermore, future models could consider noise sources at the level of sensory input, due to turbulence or stochastic binding, as well as internal signal fluctuations. In addition, these models should predict the precise relation between sensory input and motility. Another challenge still to be met is the reconstruction of the supramolecular architecture and interaction of signalling molecules in a flagellum. Such studies in other model systems such as rod photoreceptors have greatly contributed to unveil cellular strategies for signalling [32,109]. At the level of cell motility, it would be interesting to measure simultaneously the 3D flagellar shape and intracellular signals such as $\mathrm{pH}, \mathrm{V}_{\mathrm{m}}$, or $\left[\mathrm{Ca}^{2+}\right]_{\mathrm{i}}$ for sperm performing chemotaxis. Finally, it would be interesting to understand how molecular motors are synchronized or sequentially activated to produce flagellar beating waves and which mechanisms produce different beat patterns for steering.

The authors are grateful to the German Research Foundation for their financial support (DFG priority program SPP 1726 on Microswimmers - from Single Particle Motion to Collective Behaviour).

\section{References}

1. E.M. Purcell, Am. J. Phys. 45, 3 (1977)

2. L. Alvarez, B.M. Friedrich, G. Gompper, U.B. Kaupp, Trends Cell Biol. 24, 198 (2014)

3. R.G. Winkler, Eur. Phys. J. Special Topics 225, 2079 (2016)

4. M. Pichlo, S. Bungert-Plumke, I. Weyand, R. Seifert, W. Bönigk, T. Strünker, N.D. Kashikar, N. Goodwin, A. Muller, H.G. Körschen, et al., J. Cell Biol. 206, 541 (2014)

5. R. Seifert, M. Flick, W. Bonigk, L. Alvarez, C. Trotschel, A. Poetsch, A. Muller, N. Goodwin, P. Pelzer, N.D. Kashikar, et al., EMBO J. 34, 379 (2015)

6. T. Strünker, L. Alvarez, U.B. Kaupp, Curr. Opin. Neurobiol. 34, 110 (2015)

7. L. Alvarez, L. Dai, B.M. Friedrich, N.D. Kashikar, I. Gregor, R. Pascal, U.B. Kaupp, J. Cell Biol. 196, 653 (2012)

8. J.F. Jikeli, L. Alvarez, B.M. Friedrich, L.G. Wilson, R. Pascal, R. Colin, M. Pichlo, A. Rennhack, C. Brenker, U.B. Kaupp, Nat. Commun. 6, 7985 (2015)

9. K. Shiba, S.A. Baba, T. Inoue, M. Yoshida, Proc. Natl. Acad. Sci. U.S.A. 105, 19312 (2008) 
10. U.B. Kaupp, J. Gen. Physiol. 140, 583 (2012)

11. D. Carre, C. Sardet, Biol. Cell 40, 128 (1981)

12. G.E. Ward, C.J. Brokaw, D.L. Garbers, V.D. Vacquier, J. Cell Biol. 101, 2324 (1985)

13. A. Guerrero, T. Nishigaki, J. Carneiro, T. Yoshiro, C.D. Wood, A. Darszon, Dev. Biol. 344, 52 (2010)

14. N.D. Kashikar, L. Alvarez, R. Seifert, I. Gregor, O. Jackle, M. Beyermann, E. Krause, U.B. Kaupp, J. Cell Biol. 198, 1075 (2012)

15. U.B. Kaupp, J. Solzin, E. Hildebrand, J.E. Brown, A. Helbig, V. Hagen, M. Beyermann, F. Pampaloni, I. Weyand, Nat. Cell Biol. 5, 109 (2003)

16. D.L. Garbers, D.G. Lowe, L.J. Dangott, M. Chinkers, D.S. Thorpe, J.K. Bentley, C.S. Ramarao, D.V. Goeddel, S. Singh, Cold Spring Harbor Symp. Quant. Biol. LIII, $993(1988)$

17. W. Bönigk, A. Loogen, R. Seifert, N.D. Kashikar, C. Klemm, E. Krause, V. Hagen, E. Kremmer, T. Strünker, U.B. Kaupp, Sci. Signal. 2, ra68 (2009)

18. T. Strünker, I. Weyand, W. Bönigk, Q. Van, A. Loogen, J.E. Brown, N.D. Kashikar, V. Hagen, E. Krause, U.B. Kaupp, Nat. Cell Biol. 8, 1149 (2006)

19. B.E. Galindo, J.L. de la Vega-Beltran, P. Labarca, V.D. Vacquier, A. Darszon, Biochem. Biophys. Res. Commun. 354, 668 (2007)

20. H.C. Lee, D.L. Garbers, J. Biol. Chem. 261, 16026 (1986)

21. M. Nomura, V.D. Vacquier, Cell Motil. Cytoskel. 63, 582 (2006)

22. D. Wang, S.M. King, T.A. Quill, L.K. Doolittle, D.L. Garbers, Nat. Cell Biol. 5, 1117 (2003)

23. R. Gauss, R. Seifert, U.B. Kaupp, Nature 393, 583 (1998)

24. H.J. Gunaratne, V.D. Vacquier, FEBS Lett. 580, 3900 (2006)

25. Y.H. Su, V.D. Vacquier, Mol. Biol. Cell 17, 114 (2006)

26. Y.-H. Su, V.D. Vacquier, Proc. Natl. Acad. Sci. USA 99, 6743 (2002)

27. J.R. Maddock, L. Shapiro, Science 259, 1717 (1993)

28. D. Bray, M.D. Levin, C.J. Morton-Firth, Nature 393, 85 (1998)

29. T.A.J. Duke, D. Bray, PNAS 96, 10104 (1999)

30. J.E. Gestwicki, L.L. Kiessling, Nature 415, 81 (2002)

31. V. Sourjik, H.C. Berg, Nature 428, 437 (2004)

32. E.N.J. Pugh, T.D. Lamb In Handbook of Biological Physics, Volume 3, edited by D.G. Stavenga, W.J. DeGrip and E.N.J. Pugh, (North-Holland, Elsevier Science B.V., 2000), p. 183

33. K.W. Yau, R.C. Hardie, Cell 139, 246 (2009)

34. U.B. Kaupp, Nat. Rev. Neurosci. 11, 188 (2010)

35. A. Huber, P. Sander, A. Gobert, M. Bahner, R. Hermann, R. Paulsen, EMBO J. 15, 7036 (1996)

36. S. Tsunoda, J. Sierralta, Y. Sun, R. Bodner, E. Suzuki, A. Becker, M. Socolich, C.S. Zuker, Nature 388, 243 (1997)

37. K. Scott, C.S. Zuker, Nature 395, 805 (1998)

38. T.C. Rich, K.A. Fagan, H. Nakata, J. Schaack, D.M.F. Cooper, J.W. Karpen, J. Gen. Physiol. 116, 147 (2000)

39. T.C. Rich, T.E. Tse, J.G. Rohan, J. Schaack, J.W. Karpen, J. Gen. Physiol. 118, 63 (2001)

40. M. Gunkel, J. Schöneberg, W. Alkhaldi, S. Irsen, F. Noe, U.B. Kaupp, A. Al-Amoudi, Structure 23, 628 (2015)

41. D. Fotiadis, Y. Liang, S. Filipek, D.A. Saperstein, A. Engel, K. Palczewski, Nature 421, 127 (2003)

42. H.C. Berg, E.M. Purcell, Biophys. J. 20, 193 (1977)

43. H.C. Berg, Random Walks in Biology (Princeton University Press, Princeton, New Jersey, 1993)

44. M. Li, G.L. Hazelbauer, J. Bacteriol. 186, 3687 (2004)

45. V.J. Cannistraro, G.D. Glekas, C.V. Rao, G.W. Ordal, J. Bacteriol. 193, 3220 (2011)

46. V. Sourjik, N.S. Wingreen, Curr. Opin. Cell Biol. 24, 262 (2012)

47. G.E. Ward, G.W. Moy, V.D. Vacquier, Adv. Exp. Med. Biol. 207, 359 (1986) 
48. N. Suzuki, H. Shimomura, E.W. Radany, C.S. Ramarao, G.E. Ward, J.K. Bentley, D.L. Garbers, J. Biol. Chem. 259, 14874 (1984)

49. T. Doan, A. Mendez, P.B. Detwiler, J. Chen, F. Rieke, Science 313, 530 (2006)

50. A. Mendez, M.E. Burns, A. Roca, J. Lem, L.-W. Wu, M.I. Simon, D.A. Baylor, J. Chen, Neuron 28, 153 (2000)

51. G.G. Whitlock, T.D. Lamb, Neuron 23, 337 (1999)

52. O.P. Gross, Jr. E.N. Pugh, M.E. Burns, Biophys. J. 102, 1775 (2012)

53. O.P. Gross, Jr. E.N. Pugh, M.E. Burns, Neuron 76, 370 (2012)

54. G. Caruso, P. Bisegna, D. Andreucci, L. Lenoci, V.V. Gurevich, H.E. Hamm, E. DiBenedetto, Proc. Natl. Acad. Sci. USA 108, 7804 (2011)

55. V. Arshavsky, M. Burns, Cellular Logistics, e28680 (2014)

56. N.J. Cook, L.L. Molday, D. Reid, U.B. Kaupp, R.S. Molday, J. Biol. Chem. 264, 6996 (1989)

57. K.W. Yau, D.A. Baylor, Annu. Rev. Neurosci. 12, 289 (1989)

58. U.B. Kaupp, T. Niidome, T. Tanabe, S. Terada, W. Bönigk, W. Stühmer, N.J. Cook, K. Kangawa, H. Matsuo, T. Hirose, et al., Nature 342, 762 (1989)

59. C. Biskup, J. Kusch, E. Schulz, V. Nache, F. Schwede, F. Lehmann, V. Hagen, K. Benndorf, Nature 446, 440 (2007)

60. P.V. Lishko, Y. Kirichok, D. Ren, B. Navarro, J.J. Chung, D.E. Clapham, Annu. Rev. Physiol. 74, 453 (2012)

61. P.V. Lishko, I.L. Botchkina, Y. Kirichok, Nature 471, 387 (2011)

62. T. Strünker, N. Goodwin, C. Brenker, N.D. Kashikar, I. Weyand, R. Seifert, U.B. Kaupp, Nature 471, 382 (2011)

63. M.R. Miller, N. Mannowetz, A.T. Iavarone, R. Safavi, E.O. Gracheva, J.F. Smith, R.Z. Hill, D.M. Bautista, Y. Kirichok, P.V. Lishko, Science 352, 555 (2016)

64. U.B. Kaupp, R. Seifert, Annu. Rev. Physiol. 63, 235 (2001)

65. M. Biel, C. Wahl-Schott, S. Michalakis, X. Zong, Physiological Rev. 89, 847 (2009)

66. J.J.B. Jack, D. Noble, R.W. Tsien, Electric Current Flow in Excitable Cells, (Oxford University Press, 1983)

67. B. Navarro, Y. Kirichok, D.E. Clapham, Proc. Natl. Acad. Sci. U.S.A. 104, 7688 (2007)

68. V.D. Vacquier, A. Loza-Huerta, J. Garcia-Rincon, A. Darszon, C. Beltran, Biochim. Biophys. Acta. 1842, 2621 (2014)

69. T. Nishigaki, O. Jose, A.L. Gonzalez-Cota, F. Romero, C.L. Trevino, A. Darszon, Biochem. Biophys. Res. Commun. 450, 1149 (2014)

70. A. Darszon, T. Nishigaki, C. Beltran, C.L. Trevino, Physiological Rev. 91, 1305 (2011)

71. T. Nishigaki, K. Chiba, W. Miki, M. Hoshi, Zygote 4, 237 (1996)

72. M. Matsumoto, J. Solzin, A. Helbig, V. Hagen, S. Ueno, O. Kawase, Y. Maruyama, M. Ogiso, M. Godde, H. Minakata, et al., Dev. Biol. 260, 314 (2003)

73. M. Böhmer, Q. Van, I. Weyand, V. Hagen, M. Beyermann, M. Matsumoto, M. Hoshi, E. Hildebrand, U.B. Kaupp, EMBO J. 24, 2741 (2005)

74. S. Fechner, L. Alvarez, W. Bönigk, A. Müller, T.K. Berger, R. Pascal, C. Trötschel, A. Poetsch, G. Stölting, K.R. Siegfried, et al., eLife 4, e07624 (2015)

75. X. Cai, D.E. Clapham, PloS one 3, e3569 (2008)

76. V. Hagen, S. Frings, J. Bendig, D. Lorenz, B. Wiesner, U.B. Kaupp, Angew. Chem. Int. Ed. 41, 3625 (2002)

77. V. Hagen, J. Bendig, S. Frings, T. Eckardt, S. Helm, D. Reuter, U.B. Kaupp, Angew. Chem. Int. Ed. 40, 1046 (2001)

78. J. Elgeti, U.B. Kaupp, G. Gompper, Biophys. J. 99, 1018 (2010)

79. J. Elgeti, G. Gompper, Eur. Phys. J. Special Topics 225, 3033 (2016)

80. D.M. Woolley, Reprod. 126, 259 (2003)

81. B.M. Friedrich, F. Julicher, Proc. Natl. Acad. Sci. U.S.A. 104, 13256 (2007)

82. G.S. Fraenkel, D.L. Gunn, The Orientation of Animals: Kinesis, Taxes and Compass Reactions (Dover Publications, Inc., New York, 1961)

83. R. Thar, T. Fenchel, Appl. Environ. Microbiol. 67, 3299 (2001)

84. J. Riedl, M. Louis, Curr. Biol. 22, R867 (2012)

85. S. Faumont, T.H. Lindsay, S.R. Lockery, Curr. Opin. Neurobiol. 22, 580 (2012) 
86. S.R. Lockery, Curr. Opin. Neurobiol. 21, 782 (2011)

87. J. Bussmann, E. Raz, EMBO J. 34, 1309 (2015)

88. H.C. Crenshaw, Helical Orientation - a Novel Mechanism for the Orientation of Microorganisms. In Lecture Notes in Biomathematics, edited by W. Alt and G. Hofmann (Berlin, Heidelberg, New York, Springer, 1990), p. 361

89. C.J. Brokaw, J. Cell Biol. 82, 401 (1979)

90. C.B. Lindemann, K.A. Lesich, Methods Mol. Biol. 586, 337 (2009)

91. C.B. Lindemann, T.K. Gardner, E. Westbrook, K.S. Kanous, Cell Motil. Cytoskel. 20, $316(1991)$

92. C.B. Lindemann, J.S. Goltz, Cell Motil. Cytoskel. 10, 420 (1988)

93. C.D. Wood, T. Nishigaki, T. Furuta, S.A. Baba, A. Darszon, J. Cell Biol. 169, 725 (2005)

94. Y. Kambara, K. Shiba, M. Yoshida, C. Sato, K. Kitajima, C. Shingyoji, Cell Struct. Funct. 36, 69 (2011)

95. V. Torre, J.F. Ashmore, T.D. Lamb, A. Menini, J. Neurosci. the official J. Soc. Neurosci. 15, $7757(1995)$

96. K. Yoshimura, R. Kamiya, Plant Cell Physiol. 42, 665 (2001)

97. M. Delling, P.G. DeCaen, J.F. Doerner, S. Febvay, D.E. Clapham, Nature 504, 311 (2013)

98. P.G. DeCaen, M. Delling, T.N. Vien, D.E. Clapham, Nature 504, 315 (2013)

99. G.J. Pazour, N. Agrin, J. Leszyk, G.B. Witman, J. Cell Biol. 170, 103 (2005)

100. C.G. DiPetrillo, E.F. Smith, J. Cell Biol. 189, 601 (2010)

101. C. DiPetrillo, E. Smith, Methods Cell Biol. 92, 163 (2009)

102. S.M. King, Cytoskeleton (Hoboken) 67, 207 (2010)

103. H. Suzuki, T.R. Thiele, S. Faumont, M. Ezcurra, S.R. Lockery, W.R. Schafer, Nature 454, $114(2008)$

104. G. Corkidi, B. Taboada, C.D. Wood, A. Guerrero, A. Darszon, Biochem. Biophys. Res. Commun. 373, 125 (2008)

105. H.C. Crenshaw, Amer.Zool. 36, 608 (1996)

106. L. Marques, A. de Almeida, Auton. Robot. 20, 183 (2006)

107. J. Espinal, M. Aldana, A. Guerrero, C. Wood, A. Darszon, G. Martinez-Mekler, PloS one 6, e22619 (2011)

108. J. Espinal-Enriquez, A. Darszon, A. Guerrero, G. Martinez-Mekler, PloS one 9, e104451 (2014)

109. M.E. Burns, E.N.J. Pugh, Physiol. 25, 72 (2010)

\section{Appendix A. The chemical differentiator model}

The model is based on two second order chemical reactions:

$$
\mathrm{Ca}^{2+}+\mathrm{B}_{\mathrm{i}} \underset{k_{\text {off }}^{\mathrm{i}}}{\stackrel{k_{\mathrm{on}}^{\mathrm{i}}}{\longrightarrow}} \mathrm{CaB}_{\mathrm{i}},
$$

where $i=1,2$, and the reaction rates of the first reaction $(i=1)$ are faster. For simplification, we assume that:

$$
\begin{aligned}
& k_{\mathrm{on}}^{1}=k_{\mathrm{on}}^{2}(1+\delta)=k_{\mathrm{on}}(1+\delta) \\
& k_{\mathrm{off}}^{1}=k_{\mathrm{off}}^{2}(1+\delta)=k_{\mathrm{off}}(1+\delta)
\end{aligned},
$$

with $\delta>0$. Equations (A.2) and (A.3) imply that the dissociation constant $K_{D}=$ $k_{\text {off }} / k_{\text {on }}$ is identical for both reactions. In addition, we assume that the reactions are 
far from saturation, and thus, $\mathrm{B}_{1,2}$ are nearly constant. Finally, for simplicity, we assume that the total concentration of $\mathrm{B}_{1}$ and $\mathrm{B}_{2}$ are identical $\mathrm{B}_{1}=\mathrm{B}_{2}=\mathrm{B}$.

Given the mass balance equation for both reactions:

$$
\frac{\mathrm{d}\left[\mathrm{CaB}_{\mathrm{i}}\right]}{\mathrm{d} t}=k_{\text {on }}^{\mathrm{i}}\left[\mathrm{Ca}^{2+}\right][\mathrm{B}]-k_{\text {off }}^{i}\left[\mathrm{CaB}_{\mathrm{i}}\right]
$$

and equilibrium conditions $\left(\mathrm{d}\left[\mathrm{CaB}_{\mathrm{i}}\right] / \mathrm{d} t=0\right)$ :

$$
\left[\mathrm{CaB}_{\mathrm{i}}\right]_{0}=\frac{1}{K_{\mathrm{D}}}\left[\mathrm{Ca}^{2+}\right]_{0}[\mathrm{~B}]
$$

where the subscript 0 denotes concentration at equilibrium.

For $\mathrm{Ca}^{2+}$ oscillations of amplitude $\rho$ and frequency $\omega / 2 \pi$ around the concentration $\left[\mathrm{Ca}^{2+}\right]_{0}$ :

$$
\left[\mathrm{Ca}^{2+}\right]=\left[\mathrm{Ca}^{2+}\right]_{0}+\rho \cos \omega t
$$

By inserting Eqs. (A.5) and (A.6) into Eq. (A.4), we obtain:

$$
\left[\mathrm{CaB}_{\mathrm{i}}\right]=\frac{[\mathrm{B}]\left[\mathrm{Ca}^{2+}\right]_{0}}{K_{\mathrm{D}}}+\frac{k_{\mathrm{on}}^{\mathrm{i}}[\mathrm{B}] \rho}{k_{\text {off }}^{\mathrm{i}}+\omega^{2}}\left(k_{\mathrm{off}}^{\mathrm{i}} \cos \omega t+\omega \sin \omega t\right)
$$

Our model assumes that binding of $\mathrm{Ca}^{2+}$ to $\mathrm{B}_{1}\left(\mathrm{~B}_{2}\right)$ results in a proportional increase (decrease) of the curvature $C$ :

$$
C=\alpha\left(\left[\mathrm{CaB}_{1}\right]-\left[\mathrm{CaB}_{2}\right]\right),
$$

with some proportionality factor $\alpha$. Inserting Eqs. (A.2), (A.3), and (A.7) into (A.8), we obtain the following:

$$
C=\frac{\alpha k_{\mathrm{on}}[\mathrm{B}] \delta \omega \rho}{k_{\mathrm{off}}^{2}\left[(1+\delta)^{2}+\omega_{0}^{2}\right]\left[1+\omega_{0}^{2}\right]}\left[(1+\delta) \omega_{0} \cos \omega t+\left[\omega_{0}^{2}-(1+\delta)\right] \sin \omega t\right),
$$

where $\omega_{0}=\omega / k_{\text {off }}$. For the approximation $\omega_{0}<<1$, this equation leads to:

$$
C \approx \frac{\alpha[\mathrm{B}] \delta}{K_{\mathrm{D}} k_{\mathrm{off}}(1+\delta)}[-\rho \omega \sin \omega t]=\alpha^{\prime} \frac{\mathrm{d}\left[C a^{2+}\right]}{\mathrm{d} t}
$$

For binding of $\mathrm{Ca}^{2+}$ to calmodulin, and $\mathrm{Ca}^{2+}$ oscillations at a frequency of $\sim 1 \mathrm{~Hz}$, the coefficient $\omega_{0}$ is on the order of $10^{-1}-10^{-5}$ [1]. Additionally, the parameter $\delta$ could be infinitesimally small, as to the point that constants $k_{\text {on }}$ and $k_{\text {off }}$ for both reactions are indistinguishable. In fact, other mechanisms such as diffusion barriers, could serve as an effective tool to slow the kinetics of one reaction with respect to the other, yielding a small effective $\delta$. However, because $C$ is proportional to $\delta$, large changes of $C$ would be more difficult to achieve.

This demonstration can be further generalized for any $\left[\mathrm{Ca}^{2+}\right](t)$ that can be approximated by a truncated Fourier series of the form

$$
\left[\mathrm{Ca}^{2+}\right] \approx\left[\mathrm{Ca}^{2+}\right]_{0}+\sum_{n=1}^{n<<k_{o f f}} a_{n} \cos n t+\sum_{n=1}^{n<<k_{o f f}} b_{n} \sin n t
$$


Here, using the same approximations leading to Eq. (A.10), it can be found that:

$$
C \simeq \frac{\alpha[B] \delta}{K_{\mathrm{D}} k_{\text {off }}}\left[\sum_{n=1}^{n<<k_{\text {off }}} b_{n} \mathrm{n} \cos n t-\sum_{n=1}^{n<<k_{\text {off }}} a_{n} \mathrm{n} \sin \omega t\right] \approx \frac{\alpha[B] \delta}{K_{\mathrm{D}} k_{\text {off }}} \frac{\mathrm{d}\left[C a^{2+}\right]}{\mathrm{d} t}
$$

The same result can be obtained by applying the Fourier transform to Eq. (A.4), solve for $\left[\mathrm{CaB}_{\mathrm{i}}\right]$, introducing the result in Eq. (A.8), and expanding for low frequencies (Dr. Jens Elgeti, personal communication).

\section{Reference}

1. G.C. Faas, S. Raghavachari, J.E. Lisman, I. Mody, Nat. Neurosci. 14, 301 (2011)

Open Access This is an Open Access article distributed under the terms of the Creative Commons Attribution License (http://creativecommons.org/licenses/by/4.0), which permits unrestricted use, distribution, and reproduction in any medium, provided the original work is properly cited. 